\title{
Predominant Polarity in Bipolar I and II Disorders: A Five-Year Follow-Up Study
}

\author{
Sanna Pallaskorpi, MD ${ }^{a, b, c}$ \\ Kirsi Suominen, MD, $\mathrm{PhD}^{\mathrm{d}}$ \\ Tom Rosenström, $\mathrm{PhD}^{\mathrm{e} f}$ \\ Outi Mantere, MD, $\mathrm{PhD}^{g, h}$ \\ Petri Arvilommi, MD, $\mathrm{PhD}^{\mathrm{b}, \mathrm{c}}$ \\ Hanna Valtonen, MD, PhD $^{d}$ \\ Sami Leppämäki, MD, $\mathrm{PhD}^{\mathrm{a}}$ \\ Aitana García-Estela, PsyD ${ }^{j}$ \\ Iria Grande, MD, PhD ${ }^{i}$ \\ Francesc Colom, PhD \\ Eduard Vieta, MD, PhD \\ Erkki Isometsä, MD, PhD ${ }^{a, b, c}$
}

Helsinki University Central Hospital, Department of Psychiatry, Helsinki, Finland ${ }^{a}$ National Institute of Health and Welfare, Mental Health Unit, Helsinki, Finland ${ }^{b}$ University of Helsinki, Department of Psychiatry, Helsinki, Finland ${ }^{c}$

Helsinki City Department of Social Services and Healthcare, Psychiatric and Substance Abuse Services, Helsinki, Finland ${ }^{d}$

University of Helsinki, Department of Psychology and Logopedics, Helsinki, Finland

Department of Mental Disorders, Norwegian Institute of Public Health, Oslo, Norway ${ }^{f}$

McGill University, Department of Psychiatry, Quebec, Canada ${ }^{g}$

Douglas Mental Health University Institute, Bipolar Disorders Clinic, Quebec, Canada ${ }^{h}$

Bipolar Disorders Unit, Hospital Clinic, Institute of Neurosciences, University of Barcelona, IDIBAPS, CIBERSAM, Barcelona, Catalonia, Spain ${ }^{i}$

Hospital del Mar-IMIM, Mental Health Research Group, Barcelona, Catalonia, Spain 


\section{ABSTRACT}

Background: Patients with bipolar disorder (BD) differ in their relative predominance of types of episodes, yielding predominant polarity, which has important treatment implications. However, few prospective studies of predominant polarity exist.

Methods: In the Jorvi Bipolar Study (JoBS), a regionally representative cohort of 191 BD I and BD II in- and outpatients was followed for five years using life-chart methodology. Differences between depressive (DP), manic (MP), and no predominant polarity (NP) groups were examined regarding time ill, incidence of suicide attempts, and comorbidity.

Results: At baseline, $16 \%$ of patients had MP, $36 \%$ DP, and $48 \%$ NP. During the follow-up the MP group spent significantly more time euthymic, less time in major depressive episodes, and more time in manic states than the DP and NP groups. The MP group had significantly lower incidence of suicide attempts than the DP and NP group, lower prevalence of comorbid anxiety disorders but more psychotic symptoms lifetime and more often (hypo)manic first phase of the illness than the DP group. Classification of predominant polarity was influenced by the timeframe used.

Limitations: The retrospective counting of former phases is vulnerable to recall bias. Assignment of dominant polarity may necessitate a sufficient number of illness phases.

Conclusions: Predominant polarity has predictive value in predicting group differences in course of illness, but individual patients' classification may change over time. Patients with manic polarity may represent a more distinct subgroup than the two others regarding illness course, suicide attempts, and psychiatric comorbidity.

Key words: Bipolar disorder, predominant polarity, outcome, suicide attempts 


\section{Introduction}

Bipolar disorder (BD) manifests as recurrent depressive, (hypo)manic, and mixed episodes as well as subthreshold symptoms (Judd et al., 2002; Judd et al., 2003; Pallaskorpi et al., 2015). However, patients with BD differ markedly in their relative predominance of types of episodes during illness course. Such differences may have important implications for treatment decisions, including both pharmacological and non-pharmacological treatments, which differ in efficacy in treating and preventing mania and depression (Popovic et al., 2012; Popovic et al., 2013). The existence of dimensional differences within BD has long been acknowledged (Angst, 1978), but nosological focus has been on the lifetime worst manic syndromes and subdividing BD into types I and II or the soft bipolar spectrum. Only in 2006 did Colom et al. (Colom et al., 2006) introduce the first widely known classification of predominant polarity, based on differences in dominant types of illness episodes during illness history.

The definition by Colom et al. (Colom et al., 2006) set the threshold for a patient having a specific predominant polarity at two-thirds of lifetime episodes being either manic or depressive. In previous mostly cross-sectional and retrospective studies, predominantly manic (MP) or depressive polarity (DP) has been present in $42.4-71.8 \%$ of BD patients (Carvalho et al., 2014). The varying prevalences across studies can in part be explained by differences in the definitions used. Some studies have applied a less strict definition of simply having more lifetime episodes of either manic or depressive polarity (Daban et al., 2006; Forty et al., 2009; Gonzalez-Pinto et al., 2010), whereas most studies have used the definition of Colom et al. (Colom et al., 2006; Rosa et al., 2008; Garcia-Lopez et al., 2009; Mazzarini et al., 2009; Vieta et al., 2009; Murru et al., 2011; Nivoli et al., 2011; Popovic et al., 2014; Belizario et al., 2018; Vidal-Rubio et al., 2018), and only a few both (Baldessarini and Salvatore et al.2012; Azorin et al., 2015). When defining the polarity, mixed 
episodes are excluded in most studies. Carvalho et al. (Carvalho et al., 2014) reported in their systematic review the median prevalences of DP and MP to be $21.4 \%$ and $26.0 \%$, respectively. However, they noted that higher prevalence of MP was found in studies with only BD I patients and higher prevalence of DP in studies with also BD II patients. It is noteworthy that BD I patients dominate the literature on predominant polarity.

The concept of predominant polarity was created to help clinicians in planning optimal treatment based on the expected illness course in light of the past. However, only a few prospective studies have thus far been conducted (Garcia-Lopez et al., 2009; Gonzalez-Pinto et al., 2010; Belizario et al., 2018), and the actual predictive validity of the classification remains uncertain. Furthermore, the predominant polarity is defined based on the ratio of illness episodes. While this is reasonable approximation from a clinician's point of view, a limitation is that it does not consider the duration of episodes, which varies not only between but also within individuals during illness course (Grande et al., 2016). Thus, the total morbidity burden within and between patients is only partly captured by the concept of predominant polarity. Moreover, the predominant polarities could be regarded as a continuum between the extremes of manic and depressive polarity, with "no predominant polarity" (no polarity, NP) as an intermediate group (Angst, 1978; Angst, 2007; Qiu et al., 2017). This dimensional view of predominant polarity and the role of the intermediate no polarity group has been only recently addressed in the literature (Belizario et al., 2018; VidalRubio et al., 2018).

The predominant polarity is defined by the preceding course of $\mathrm{BD}$, but it may well be associated with other important clinical features such as comorbid mental disorders or risk of suicide attempts. A history or higher number of suicide attempts (Colom et al., 2006; Gonzalez-Pinto et al., 2010; Baldessarini and Undurraga et al.2012; Popovic et al., 2014) has repeatedly been linked 
to DP, and moreover, when mixed states were combined with the depressive category, the association with suicide attempts almost doubled (Baldessarini and Undurraga et al.2012). In contrast, Azorin et al. (Azorin et al., 2015) found the MP group to have more suicide attempts and explained this by higher levels of cyclothymic and hyperthymic temperaments in MP. A 7-year longitudinal cohort study also found higher number of SAs in the MP group (Belizario et al., 2018). Some studies have reported the occurrence of anxiety disorders (Azorin et al., 2015) and DSM-IV axis II comorbidity (Baldessarini and Undurraga et al.2012) to be more frequent in the DP group, while others have not found association with (current) comorbid mental disorders and polarity dominance (Koyuncu et al., 2010; Murru et al., 2011; Popovic et al., 2014). However, as the current illness phase is known to strongly covary with the prevalence of psychiatric comorbidity both cross-sectionally and longitudinally (Mantere et al., 2010; Pavlova et al., 2015), the association of comorbid internalizing disorders with DP and externalizing disorders with MP is plausible.

There is at present an accumulating literature on patterns of clinical correlates of predominant polarity (Carvalho et al., 2014; Garcia-Jimenez et al., 2017). However, findings of these studies have not been fully consistent, and these associations have seldom been tested in prospective studies.

To our knowledge, no previous studies including both BD I and II patients have examined the predictive validity of predominant polarity in terms of time ill, and only few the incidence of suicide attempts or the stability of the classification in the long-term follow-up. We hypothesized that (a) retrospective and prospectively defined predominant polarities would be consistent; that (b) patients with depressive predominant polarity would spend more time depressed and (c) have more suicide attempts than patients with manic predominant polarity; and that (d) patients with manic predominant polarity would more often have suffered from lifetime comorbid substance 
abuse disorders and patients with depressive predominant polarity more often from lifetime comorbid anxiety disorders.

\section{Methods}

\section{Screening and baseline evaluation}

The Jorvi Bipolar Study (JoBS) is a collaborative research project of the Department of Mental Health and Substance Abuse Services, National Institute of Health and Welfare, Helsinki, and the Department of Psychiatry, Jorvi Hospital, Espoo, Finland. The Department of Psychiatry at Jorvi Hospital provides secondary care psychiatric services to the catchment area's citizens. The study protocol was approved by the Ethics Committee of Helsinki and Uusimaa Healthcare District. The methodology of JoBS has been described elsewhere in detail ( Mantere et al., 2010; Pallaskorpi et al., 2015).

In brief, by using the Mood Disorder Questionnaire (MDQ) (Hirschfeld et al., 2000)(29), all patients in the catchment area of Jorvi Hospital with possible new DSM-IV BD episodes were screened. A positive screen or clinical suspicion of BD resulted in confirming the diagnosis by using the Structured Clinical Interview for DSM-IV Disorders (SCID-I/P) (First et al., 2002) after informing the subject about the study protocol and requesting written consent. All possible information, such as psychiatric records, interviews with family members, and observations of attending personnel, was used. The final sample included 191 patients with an ongoing mood episode. A retrospective life-chart and psychiatric records were used to gather former illness history, including the number of lifetime mood episodes. Data on former and current suicidality, demographic characteristics, and treatment received were collected. Lifetime and current comorbid diagnoses were assessed by using SCID-I (First et al., 2002) and SCID-II (First et al., 
1997) interviews. Other tools used at baseline comprised the Young Mania Rating Scale (YMRS) (Young et al., 1978) (32), the 17-item Hamilton Depression Scale (HAM-D) (Hamilton, 1960), the 21-item Beck Depression Inventory (BDI) (Beck et al., 1961), the Beck Anxiety Inventory (BAI) (Beck et al., 1988), the Beck Hopelessness Scale (HS) (Beck et al., 1974), the Scale for Suicidal Ideation (SSI) (Beck et al., 1979), the DSM-IV Social and Occupational Functional Assessment Scale (SOFAS) (Goldman et al., 1992), the Perceived Social Support Scale-Revised (Blumenthal et al., 1987), and the short Eysenck's Personality Inventory (Al-Issa, 1964).

\section{Follow-up}

A detailed description of the follow-up methodology has been presented in previous reports (Pallaskorpi et al., 2015; Mantere et al., 2008). In interviews at 6 and 18 months and at 5 years, the duration and timing of major depressive, hypomanic, manic, mixed, depressive mixed, cyclothymic, and substance-induced phases of BD were retrospectively identified by using a lifechart method similar, but not identical to the Longitudinal Interval Follow-up Evaluation (Keller et al., 1987). Using probes related to important life events, change points in the psychopathological states were explored to maximize the accuracy of the assessment. The definitions of DSM-IV for mood episodes were used with two exceptions: (i) the minimum duration of hypomania was 2 days instead of 4 days and (ii) the depressive mixed state was defined according to the definition of Benazzi and Akiskal (Benazzi and Akiskal2001) (i.e. $\geq 3$ simultaneous hypomanic symptoms present for at least half of the time during a major depressive episode [MDE]). States of subsyndromal symptoms (depressive or hypomanic) were rated when neither the full criteria for an illness phase nor euthymia were present. At all follow-up interviews, SCID-I (First et al., 2002) and SCID-II (First et al., 1997) were conducted and the forementioned scales and tools were used 
to gather information on comorbid disorders, psychosocial factors, symptom severity, and suicidality. Information was gathered in a graphic life-chart.

In this study, we excluded as outliers three patients (1.6\%) with reportedly more than 100 lifetime mood episodes by baseline because of imprecision in numbers and types of illness phases. Thus, 188 patients (98.4\%) of the original cohort of 191 were included when retrospectively defining the predominant polarity and analyzing the cross-sectional baseline data. The prospective follow-up data for mood episodes and suicide attempts were available for 175 patients (91.6\%) who were included in the analysis of time ill and incidence of suicide attempts. The median follow-up time was 62.4 months and the mean number of suicide attempts 0.51 (median 0.00 ). The patients not included in the follow-up $(\mathrm{N}=16)$ did not differ from those who were included $(\mathrm{N}=175)$ in terms of gender (male 31.3\% vs. 48.6\%, p=0.184), BD type (type I 62.5\% vs. 45.7\%, p=0.198), lifetime psychotic symptoms (62.5\% vs. 49.7\%, $p=0.327)$, former suicide attempts (50.0\% vs. $51.4 \%$, $p=0.913)$, some lifetime anxiety disorder (56.3\% vs. 53.1\%, $p=0.812)$, lifetime substance use disorder (56.3\% vs. 50.3\%, $p=0.648)$, being inpatients at baseline ( $43.8 \%$ vs. $33.1 \%, p=0.391)$, or having depressive first episode (37.5\% vs. $52.5 \%, p=0.248)$. Excluding the three outliers, the subjects not included in the follow-up did not differ in terms of number of earlier episodes ( $t=0.59$, $p=0.556)$. When examining the stability of the dominant polarity categories, patients with no illness phases in follow-up $(\mathrm{N}=30,17.1 \%)$ were excluded.

\section{Definition of predominant polarity}

We defined predominant polarity according to Colom et al. (Colom et al., 2006), requiring twothirds of the past episodes to be either (hypo)manic or depressive in order to have a dominant polarity. Time of the baseline interview was used as a cut-point when counting the phases 
(minimum 1, maximum 84, median 10), and the index phase was included. The distribution of predominant polarity groups according to different categorization is seen in Table 1. When conducting the analyses, we used the categorization where mixed phases were combined with manic and hypomanic phases, and depressive mixed phases were combined with major depressive episodes (MDEs) (Definition 2 in Table 1). This is in accordance with DSM-5 (American Psychiatric Association, 2013), which replaced the former term "mixed episode" with a mixedfeatures specifier that can be applied to episodes of major depression, hypomania, or mania. However, we also conducted sensitivity analyses excluding the mixed phases (still including them in the total sum of the phases; Definition 1, Table 1).

\section{Statistical methods}

The Chi-square or Kruskall-Wallis test was used when examining the sociodemographic and clinical characteristics between the three polarity groups, and Kruskall-Wallis test when examining the differences in time spent ill. Poisson regression was used when comparing the incidence of suicide attempts, the number of phases, and the number of hospitalizations in the follow-up. These analyses were conducted in two ways, using first the NP group and then the DP group as a reference category. Multinomial logistic regression was used when comparing the differences in clinical variables and occurrence of comorbid disorders between the groups. Polychoric correlation analysis with R package "polycor" (version 0.7-9) was used to examine the stability of the polarity types. Polychoric correlations refer to correlations of underlying normally distributed liability variables as estimated from ordinal data. Otherwise, IBM SPSS version 24 (SPSS Inc., Chicago, IL, USA) was used. 


\section{Results}

Overall, about half of all patients, 98 of $188(52 \%)$, had a predominant polarity. In 30 patients (16\%), the predominant polarity was manic, in 68 (36\%) depressive, and in $90(48 \%)$ no predominant polarity was assigned (Table 1). In the baseline sociodemographic and clinical characteristics, significant differences between the three groups were found in BD type, type of index phase, type of first illness phase, occurrence of lifetime psychotic symptoms, anxiety disorders, and substance abuse disorders, and outpatient versus inpatient status at intake (Table 2). During follow-up $44.4 \%$ of the MP group, $40.5 \%$ of the NP group, and $34.8 \%$ of the DP group had at least one hospital admission. In Poisson regression analyses, no difference emerged in the number of hospitalizations during follow-up between the MP, NP, and DP groups (means 1.7, 1.2, and 0.7 , respectively, median 0.00 for all groups) when age, gender, and BD type were adjusted. However, there was a tendency for patients in the MP group to have more hospital admissions than patients in the DP group $(B=0.441, p=0.056)$. Furthermore, patients in the NP group were most often inpatients at intake (Table 1). Inpatients in the MP group were hospitalized exclusively for manic $(88.9 \%)$ or mixed state $(11.1 \%)$, in the DP group more often for MDE $(71.4 \%)$ than for manic (14.2\%) or mixed state (14.3\%), and in the NP group more often for MDE (65.0\%) than for manic $(25.0 \%)$ or mixed state $(10.0 \%)$.

\section{Predictive validity of predominant polarity in time ill and number of phases in follow-up}

The time spent in different illness states during the 5-year follow-up for the manic, depressive, and no polarity groups is seen in Figure 1. Within the whole sample $(\mathrm{N}=175)$, the three groups differed in proportions of time spent euthymic (median proportions in follow-up for MP $76.7 \%$, for NP $38.7 \%$, and for DP $28.2 \%, \mathrm{H}=18.731, \mathrm{df}=2, \mathrm{p}<0.001$ ), in MDEs (median proportions in follow-up 
$3.5 \%, 22.8 \%$, and $30.0 \%$, respectively, $\mathrm{H}=24.407, \mathrm{df}=2, \mathrm{p}<0.001$ ), and in manic states (median proportions in follow-up $3.7 \%, 1.1 \%$, and $1.0 \%$, respectively, $\mathrm{H}=7.373, \mathrm{df}=2, \mathrm{p}=0.025$ ). In subgroup analyses, these differences remained statistically significant within the $B D$ I group $(N=80$, $p$-values $0.005,0.002$, and 0.037 , respectively), but among the $B D$ II patients $(\mathrm{N}=95)$ only the difference in time spent in MDEs $(p=0.008)$.

In post hoc pairwise Kruskall-Wallis comparisons, the MP group spent more time in euthymia than the DP group ( $p<0.000$ ) or NP group ( $p=0.001)$, less time in MDEs than the DP group $(p<0.000)$ or NP group $(p<0.000)$, and more time in manic states than the DP group $(p=0.019)$ or NP group $(p=0.008)$.

In Poisson regression models, adjusted for BD type, age, and gender, the DP group had smaller total number of phases in follow-up than the NP group $(B=-0.223, p=0.005)$ and less MDEs than the NP group $(B=-0.250, p=0.022)$. The MP group had more manic phases than the NP group $(B=0.519, p<0.001)$ or DP group $(B=0.747, p<0.001)$, less MDEs than the NP group $(B=-0.615$, $p<0.001)$ or DP group $(B=-0.365, p=0.049)$, and less mixed phases than the NP group $(B=-0.779$, $\mathrm{p}=0.025)$.

\section{Stability of polarity types in follow-up}

When predominant polarity was defined using the number of phases from the time of the first illness phase to baseline (median time 12.1 years) versus the number of phases in the 5 -year prospective follow-up (median follow-up time 5.3 years, $\mathrm{N}=145$ ), predominant polarity remained the same for $42.7 \%$ of the cohort (Table 4 ). The polychoric correlation for the stability was 0.407 , meaning that a latent polarity continuum explained $0.407^{2} \times 100 \% \approx 16.6 \%$ of the follow-up polarity continuum. When the patients with less than three phases in follow-up were excluded, 
the predominant polarity remained the same for $47 \%$ of the patients in the follow-up. However, when comparing the predominant polarity defined with the count of phases before baseline with that of the whole illness duration from the first illness phase to the end of the 5 -year follow up (excluding the patients with no phases in follow-up) the stability increased to $75.9 \%$, or to $78.1 \%$ (excluding also those with less than three phases before baseline).

$\underline{\text { Impact of predominant polarity on suicide attempts in follow-up }}$

The incidences of suicide attempts in different polarity groups in the 5 -year follow-up are presented in Figure 2. The overall incidence rate per 1000 patient-years was 126 (95\% Cl 102-155). The incidence for the MP group was the lowest, 32/1000 person-years ( $95 \% \mathrm{Cl} 12-86)$, followed by the incidence of $127 / 1000$ person-years for the NP group ( $95 \% \mathrm{Cl} 94-172$ ) and 170/1000 personyears for the DP group ( $95 \% \mathrm{Cl} 126-228)$.

In Poisson regression analysis, patients in the MP group had significantly fewer suicide attempts than patients in either the DP group $(B=-1.660, p=0.001)$ or the NP group $(B=-1.366, p=0.009)$. These results remained but were attenuated when age, BD type, gender, and time spent in highrisk states for suicide attempts (MDE and mixed states) were controlled.

\section{$\underline{\text { Impact of predominant polarity on comorbidity and other clinical variables }}$}

The results of the univariate multinomial regression model are presented in Table 3. The MP group had lower prevalence of lifetime comorbid anxiety disorders, more often (hypo)manic first phase of the illness, and less frequently MDE as the first phase of the illness relative to the DP group in the adjusted model. In the non-adjusted model, more frequent occurrence of lifetime 
psychotic symptoms was associated with the MP group, and more frequent occurrence of comorbid lifetime substance abuse with the NP group. 


\section{Discussion}

In this prospective study, we followed a regionally representative cohort of secondary care BD I and II patients for five years. Based on retrospective information, about one-sixth of the patients had a predominantly manic (MP), one-half intermediate (no polarity, NP), and one-third a depressive polarity (DP) pattern. While there were significant differences in time spent ill during follow-up between the polarity groups, consistency of their categorical classification was less impressive. However, the incidence of suicide attempts in follow-up was over fivefold in the depressive polarity group relative to the manic polarity group. The groups were found to differ expectedly in terms of lifetime comorbidity with anxiety disorder, but not substance use. Overall, including the intermediate no polarity group, the analyses revealed that the manic predominant polarity group had a better prognosis than the other two groups, which resembled each other more.

The major strength of this study is the prospective life-chart methodology, which allowed us to define the length and timing of different mood episodes and subthreshold symptoms, as well as the occurrence and timing of suicide attempts in follow-up. This study design also allowed accounting for the patients' different follow-up times of and to examining the predictive validity of predominant polarity at the level of time spent in varying illness states. The epidemiologically representative secondary level psychiatric care sample includes in- and outpatients with BD I and BD II in all possible index episodes. Patients without a clinical diagnosis of BD were also included by first screening with MDQ (Hirschfeld et al., 2000) and then diagnosing by SCID-I/P (First et al., 2002). Furthermore, their comorbid disorders were carefully examined by using SCID-I/P (First et al., 2002) and SCID-II interviews (First et al., 1997). What constitutes a long-term follow-up is a 
relative matter, but five years seems to be long enough e.g. to eliminate the effect of index episode on important outcomes such as time ill (Mantere et al., 2008; Pallaskorpi et al. 2015).

Some limitations should be addressed as well. The retrospective counting of former phases at baseline is vulnerable to recall bias, but this is a general problem in cross-sectional studies defining predominant polarity. Although prospective in nature, the study design allowed only retrospective assessments of mood episodes and suicide attempts in interviews at 6 months, 18 months, and 5 years, which might predispose to underreporting of short and milder illness phases. However, information in interviews was collected from multiple sources, including patient records and observations of personnel and relatives. The sample size is moderate and despite massive efforts to reach all original participants, the loss of patients by the 5 -year interview could not be totally avoided, but only 14/191 patients (7.3\%) missed all three follow-up interviews. The moderate sample size might limit the statistical power in some analyses. The cohort also included patients with very recent onset of illness, and some patients had no or very few prospective illness phases. Assignment of dominant polarity may necessitate a sufficient number of illness phases in order not to become spurious. Finally, this study was naturalistic, and the influence of the treatment could not be controlled.

We found that patients in different predominant polarity groups differed in their clinical outcome. Patients in the MP group had better outcome than those in the other two groups in many respects. In accordance with a retrospective study of Vidal-Rubio et al. (Vidal-Rubio et al., 2018), we found the MP group to spent more time in euthymia. They also spent less time in MDEs and more in manic states. However, probably since there are multiple indications for hospitalization among BD patients, contrary to study of Belizario et al. (Belizario et al., 2018), this did not lead to higher frequency of hospitalizations. In specific subgroup analyses, the differences 
in time ill were significant in the BD I group, but for the BD II group the findings persisted only for the time spent in MDEs, almost reaching significance also for the time spent euthymic. In terms of numbers of illness phases, the MP group had a smaller number of MDEs and more manic phases in follow-up than the other groups. This is in accordance with previous findings in the 10-year follow-up of Gonzalez-Pinto et al. (Gonzalez-Pinto et al., 2010) and in the 7-year follow-up of Belizario et al. (Belizario et al., 2018). However, in the total number of phases during the follow-up we found differences only between the DP group and the NP group. The intermediate NP group had more illness phases overall, as well as more MDEs specifically, but no difference between these two groups was observed in time spent ill. Contrary to the study of Vieta et al. (Vieta et al., 2009), we found at baseline no difference in the occurrence of rapid cycling between the groups (Table 1). Our finding of the MP group having more lifetime psychotic symptoms (in the nonadjusted model) may be due to psychotic mania or psychotic depression, but is concordant with previous studies showing that MP is associated with a first illness episode with psychotic features (Popovic et al., 2014; Baldessarini and Undurraga et al.2012), lifetime psychotic symptoms (Popovic et al., 2014) and higher number of episodes with psychotic symptoms in follow-up (Belizario et al., 2018). The effects of treatment were not controlled and there are probably more effective treatment options for manic than depressive states (Yatham et al., 2018; Vieta et al., 2018).Thus, the treatment effects might have contributed to the more favorable course of the MP group. However, this merely reflects clinical reality.

If classification of predominant polarity is to be clinically useful, it must be reliable and have predictive validity. We found that predominant polarity predicted group-level differences in times ill, but consistency between retrospective and prospective polarity assignment was lower than in the 7-year follow-up of Belizario et al (Belizario et al., 2018). It improved slightly by excluding cases with less than three phases during follow-up (from $43 \%$ to $47 \%$ ). However, classification of 
predominant polarity remained the same in $76 \%$ of cases when those assigned at baseline were compared with those at the end of follow-up, when the whole illness history up to the end of the follow-up was observed. These findings indicate that validity of the classification is strongly influenced by the time frame used, and the evaluation of predominant polarity can be reliably undertaken only after some illness phases have passed. This is problematic since for clinical purposes such evaluations should be done as early as possible to prevent chronicity. In accord with many previous studies (Colom et al., 2006; Daban et al., 2006; Rosa et al., 2008; Forty et al., 2009; Mazzarini et al., 2009; Baldessarini and Undurraga et al.2012; Popovic et al., 2014; Azorin et al., 2015; Janiri et al., 2017), we found an association between the predominant polarity and the polarity of the first illness episode, which might be a useful predictor early in the course of bipolar illness. The optimal time-point for evaluation of predominant polarity remains to be elucidated by future studies.

Predominant polarity predicted several-fold differences in incidence of suicide attempts during the follow-up, which is both an important aspect of predictive validity and important clinically. Although we did not find an association between retrospective lifetime history of suicide attempts and predominant polarity, the finding of the MP group having less suicide attempts in follow-up is in line with many earlier studies (Colom et al., 2006; Gonzalez-Pinto et al., 2010; Popovic et al., 2014) but contrary to a recent prospective study, which found higher number of suicide attempts among the MP group (Belizario et al., 2018). We found the incidence to exist along a continuum from the MP group to the DP group, with the NP group situated between these two groups (Figure 1). The MP group had less suicide attempts than the other two groups, which did not differ significantly from each other. The impact of the mixed states on suicidality is of interest; Baldessarini et al. (Baldessarini and Undurraga et al.2012) found that when mixed states were combined with the depressive category, the association of the DP group with suicide 
attempts almost doubled. This is in accordance with the vast differences discovered in the incidences of suicide attempts during different illness states, with mixed phases having the highest risk (Pallaskorpi et al., 2017). We classified the mixed states (see Definition 2, Table 1) in accordance with the DSM-5 (American Psychiatric Association, 2013), which influences comparisons of some outcome measures with previous studies. However, our key findings were influenced only marginally by sensitivity analyses that excluded mixed phases.

The intermediate NP group has received scant attention in earlier research (Belizario et al., 2018). The definition of predominant polarity considers only the ratio of the illness states, not the number of episodes. So, in theory, patients in this intermediate group could suffer from a more serious course of illness with regard to factors such as number of episodes, rapid cycling, time ill, and occurrence of comorbid disorders. According to our findings, the NP group resembles the DP group in many respects. However, the NP group had more lifetime comorbid substance abuse disorders than the DP group in the non-adjusted model and they also were more often inpatients at intake. We found no difference in time spent in manic states, MDEs, or euthymia during the follow-up between these two groups. Nor was there a difference in the total number of phases before baseline when the duration of illness history was adjusted, but in the follow-up the NP group had more MDEs and more phases altogether than the DP group. In clinical practice, MP might be a more powerful predictor of (better) illness course than DP, which appears only partly distinguishable from the NP group. Patients with depressive illness course need more prompt monitoring for suicidality, the presence of mixed features highlighting this need further and also having potential prognostic and therapeutic implications (Pacchiarotti et al., 2011; Pacchiarotti et al., 2013; Popovic et al., 2014). 
We found predominant polarity to be associated with psychiatric comorbidity. Only a few studies, mostly with negative findings exist on the occurrence of comorbid disorders related to predominant polarity. Our finding of the MP group having lower lifetime prevalence of comorbid anxiety disorders than the DP group is consistent with that of Azorin et al. (Azorin et al., 2015), a recent meta-analysis (Garcia-Jimenez et al., 2017) and our previous finding of strong covariation of depression and anxiety over the course of BD (Mantere et al., 2010). Some of the earlier studies combined the anxiety disorders and substance use disorders as "Axis I disorders", which may explain their negative results, since these two disorders may have contradictory associations with predominant polarity. However, the results concerning substance use disorders (SUDs) and the predominant polarity are conflicting. The SUDs and drug abuse before the first illness episode of BD have been associated with MP (Colom et al., 2006; Popovic et al., 2014; Garcia-Jimenez et al., 2017), and our previous study indicates that SUDs seem to covary strongly with manic symptoms along illness course (Mantere et al., 2010). In contrast, Janiri et al. (Janiri et al., 2017) noted that BD patients without SUDs more often had MP, while BD patients with alcohol use disorder or polysubstance use more often had DP. We observed no difference in the occurrence of lifetime comorbid SUDs between the MP and DP groups. Long-term studies that take into account also the influence of current mood state are needed to clarify the relationship between SUDs and predominant polarity.

\section{Conclusion}

In this long-term study, we found that the classification of BD I and BD II in- and outpatients according to their predominant polarity has predictive validity, but in a significant minority of patients their classification status may change. Patients with manic predominant polarity may represent a more distinct subgroup, having a better prognosis in terms of time euthymic, 
incidence of suicide attempts, and prevalence of comorbid anxiety disorders, but may more often suffer from psychotic symptoms. In contrast, the depressive and intermediate no predominant polarity groups may be only partly distinguishable from each other.

\section{Conflict of interest}

None

\section{Authors' contributions}

$\mathrm{SP}, \mathrm{KS}, \mathrm{OM}, \mathrm{PA}, \mathrm{HV}, \mathrm{SL}$ and $\mathrm{El}$ are part of the JoBS research team. SP, KS, TR and El designed the study, discussing it with AGE, IG, FC and EV. SP and TR undertook the analysis of this manuscript and SP wrote the first draft of the manuscript. All authors discussed the results and implications and commented on the manuscript. All authors have contributed to and approved the final manuscript.

\section{Funding source}

This study was supported by grants from Finnish Medical Society and Finnish Foundation for Psychiatric Research. IG is supported by the Instituto de Salud Carlos III, Ministry of Economy and Competitiveness of Spain (Juan Rodés Contract (JR15/00012) and a grant (Pl16/00187)) integrated into the Plan Nacional de I+D+I and cofunded by ISCIII-Subdirección General de Evaluación and Fondo Europeo de Desarrollo Regional (FEDER). EV is supported by the Spanish Ministry of Economy and Competitiveness ( $\mathrm{Pl}_{15} / 00283$ ) integrated into the Plan Nacional de I+D+l y cofinanciado por el ISCIII-Subdirección General de Evaluación y el Fondo Europeo de Desarrollo Regional (FEDER); CIBERSAM; and the Comissionat per a Universitats i Recerca del DIUE de la Generalitat de Catalunya to the Bipolar Disorders Group (2017 SGR 1365) and the project SLTo06/17/00357, from PERIS 2016-2020 (Departament de Salut), CERCA Programme/Generalitat de Catalunya.

\section{Acknowledgements}

We express our gratitude to the study participants. 


\section{References}

Al-Issa, I., 1964. The Eysenck Personality Inventory in Chronic Schizophrenia. Br. J. Psychiatry. 110, 397-400.

American Psychiatric Association, 2013. Diagnostic and Statistical Manual of Mental Disorders (5th Edition).

Angst, J., 1978. The course of affective disorders. II. Typology of bipolar manic-depressive illness. Arch. Psychiatr. Nervenkr. (1970). 226, 65-73.

Angst, J., 2007. The bipolar spectrum. Br. J. Psychiatry. 190, 189-191.

Azorin, J.M., Adida, M., Belzeaux, R., 2015. Predominant polarity in bipolar disorders: Further evidence for the role of affective temperaments. J. Affect. Disord. 182, 57-63.

Baldessarini, R.J., Salvatore, P., Khalsa, H.K., Imaz-Etxeberria, H., Gonzalez-Pinto, A., Tohen, M., 2012. Episode cycles with increasing recurrences in first-episode bipolar-I disorder patients. J. Affect. Disord. 136, 149-154.

Baldessarini, R.J., Undurraga, J., Vazquez, G.H., Tondo, L., Salvatore, P., Ha, K., Khalsa, H.M., Lepri, B., Ha, T.H., Chang, J.S., Tohen, M., Vieta, E., 2012. Predominant recurrence polarity among 928 adult international bipolar I disorder patients. Acta Psychiatr. Scand. 125, 293-302.

Beck, A.T., Ward, C.H., Mendelson, M., Mock, J., Erbaugh, J., 1961. An inventory for measuring depression. Arch. Gen. Psychiatry. 4, 561-571.

Beck, A.T., Weissman, A., Lester, D., Trexler, L., 1974. The measurement of pessimism: the hopelessness scale. J. Consult. Clin. Psychol. 42, 861-865.

Beck, A.T., Kovacs, M., Weissman, A., 1979. Assessment of suicidal intention: the Scale for Suicide Ideation. J. Consult. Clin. Psychol. 47, 343-352.

Beck, A.T., Epstein, N., Brown, G., Steer, R.A., 1988. An inventory for measuring clinical anxiety: psychometric properties. J. Consult. Clin. Psychol. 56, 893-897.

Belizario, G.O., Silva, M., Lafer, B., 2018. Impact of predominant polarity on long-term outcome in bipolar disorder: A 7-year longitudinal cohort study. J. Affect. Disord. 241, 37-40.

Benazzi, F. and Akiskal, H.S., 2001. Delineating bipolar II mixed states in the Ravenna-San Diego collaborative study: the relative prevalence and diagnostic significance of hypomanic features during major depressive episodes. J. Affect. Disord. 67, 115-122.

Blumenthal, J.A., Burg, M.M., Barefoot, J., Williams, R.B., Haney, T., Zimet, G., 1987. Social support, type A behavior, and coronary artery disease. Psychosom. Med. 49, 331-340. 
Carvalho, A.F., Mclntyre, R.S., Dimelis, D., Gonda, X., Berk, M., Nunes-Neto, P.R., Cha, D.S., Hyphantis, T.N., Angst, J., Fountoulakis, K.N., 2014. Predominant polarity as a course specifier for bipolar disorder: a systematic review. J. Affect. Disord. 163, 56-64.

Colom, F., Vieta, E., Daban, C., Pacchiarotti, I., Sanchez-Moreno, J., 2006. Clinical and therapeutic implications of predominant polarity in bipolar disorder. J. Affect. Disord. 93, 13-17.

Daban, C., Colom, F., Sanchez-Moreno, J., Garcia-Amador, M., Vieta, E., 2006. Clinical correlates of first-episode polarity in bipolar disorder. Compr. Psychiatry. 47, 433-437.

First M.B., Spitzer R.L., Gibbon M., Williams J.B.Structured Clinical Interview for DSM-IV-TR Axis I Disorders, Research Version, Patient Edition with Psychotic Screen. New York, NY: Biometrics Research, New York State Psychiatric Institute 2002.

First M.B., Spitzer R.L., Gibbon M., Williams J.B. Structured Clinical Interview for DSM-IV Axis II Personality Disorders (SCID-II). New York, NY: Biometrics, New York State Psychiatric Institute 1997.

Forty, L., Jones, L., Jones, I., Smith, D.J., Caesar, S., Fraser, C., Gordon-Smith, K., Hyde, S., Craddock, N., 2009. Polarity at illness onset in bipolar I disorder and clinical course of illness. Bipolar Disord. 11, 82-88.

Garcia-Jimenez, J., Alvarez-Fernandez, M., Aguado-Bailon, L., Gutierrez-Rojas, L., 2017. Epidemiological and clinical variables related with the predominant polarity on bipolar disorder: A systematic review. Rev. Psiquiatr. Salud Ment. 286.

Garcia-Lopez A., de Dios-Perrino C., Ezguiaga E., 2009. Polarity of the first episode and predominant polarity in a cohort of bipolar outpatients. Eur Neuropsychopharmacol., 571.

Goldman, H.H., Skodol, A.E., Lave, T.R., 1992. Revising axis V for DSM-IV: a review of measures of social functioning. Am. J. Psychiatry. 149, 1148-1156.

Gonzalez-Pinto, A., Alberich, S., Barbeito, S., Alonso, M., Vieta, E., Martinez-Aran, A.m Saenz, M., Lopez, P., 2010. Different profile of substance abuse in relation to predominant polarity in bipolar disorder: The Vitoria long-term follow-up study. J. Affect. Disord. 124, 250-255.

Grande, I., Berk, M., Birmaher, B., Vieta, E., 2016. Bipolar disorder. Lancet. 387, 1561-1572.

Hamilton, M., 1960. A rating scale for depression. J. Neurol. Neurosurg. Psychiatry. 23, 56-62.

Hirschfeld, R.M., Williams, J.B., Spitzer, R.L., Calabrese, J.R., Flynn, L., Keck, P.E., Lewis, L., McElroy, S.L., Post, R.M., Rapport, D.J., Russell, J.M., Sachs, G.S., Zajecka, J., 2000. Development and validation of a screening instrument for bipolar spectrum disorder: the Mood Disorder Questionnaire. Am. J. Psychiatry. 157, 1873-1875.

Janiri, D., Di Nicola, M., Martinotti, G., Janiri, L., 2017. Who's the Leader, Mania or Depression? Predominant Polarity and Alcohol/Polysubstance Use in Bipolar Disorders. Curr.

Neuropharmacol. 15, 409-416. 
Judd, L.L., Akiskal, H.S., Schettler, P.J., Endicott, J., Maser, J., Solomon, D.A., Leon, A.C., Rice, J.A., Keller, M.B., 2002. The long-term natural history of the weekly symptomatic status of bipolar I disorder. Arch. Gen. Psychiatry. 59, 530-537.

Judd, L.L., Akiskal, H.S., Schettler, P.J., Coryell, W., Endicott, J., Maser, J.D., Solomon, D.A., Leon, A.C., Keller, M.B., 2003. A prospective investigation of the natural history of the long-term weekly symptomatic status of bipolar II disorder. Arch. Gen. Psychiatry. 60, 261-269.

Keller, M.B., Lavori, P.W., Friedman, B., Nielsen, E., Endicott, J., McDonald-Scott, P., Andreasen, N.C., 1987. The Longitudinal Interval Follow-up Evaluation. A comprehensive method for assessing outcome in prospective longitudinal studies. Arch. Gen. Psychiatry. 44, 540-548.

Koyuncu, A., Tukel, R., Ozyildirim, I., Meteris, H., Yazici, O., 2010. Impact of obsessive-compulsive disorder comorbidity on the sociodemographic and clinical features of patients with bipolar disorder. Compr. Psychiatry. 51, 293-297.

Mantere, O., Suominen, K., Valtonen, H., M.Arvilommi, P., Leppamaki, S., Melartin, T., Isometsä, E., 2008. Differences in outcome of DSM-IV bipolar I and II disorders. Bipolar Disord. 10, 413-425.

Mantere, O., Isometsä, E., Ketokivi, M.Kiviruusu, O.Suominen, K.Valtonen, H.M.Arvilommi, P., Leppamäki, S., 2010. A prospective latent analyses study of psychiatric comorbidity of DSM-IV bipolar I and II disorders. Bipolar Disord. 12, 271-284.

Mazzarini, L., Pacchiarotti, I., Colom, F., Sani, G., Kotzalidis, G.D., Rosa, A.R., Sanna, L., De Rossi, P., Girardi, N., Bonnin, C.M., Sanchez-Moreno, J., Vazquez, G.H., Gasto, C., Tatarelli, R., Vieta, E., 2009. Predominant polarity and temperament in bipolar and unipolar affective disorders. J.

Affect. Disord. 119, 28-33.

Murru, A., Pachiarotti, I., Verdolini, N., Reinares, M., Torrent, C., Geoffroy, P., Bellivier, F., Llorca, P.M., Vieta, E. , Samalin, L., 2011. Clinical, functional and therapeutic implications of comorbid personality disorders in a sample of bipolar patients. Eur Neuropsychopharmacol., 432-433.

Nivoli, A.M., Pacchiarotti, I., Rosa, A.R., Popovic, D., Murru, A., Valenti, M., Bonnin, C.M., Grande, I., Sanchez-Moreno, J., Vieta, E., Colom, F., 2011. Gender differences in a cohort study of 604 bipolar patients: the role of predominant polarity. J. Affect. Disord. 133, 443-449.

Pacchiarotti, I., Mazzarini, L., Kotzalidis, G.D., Valenti, M., Nivoli, A.M., Sani, G., Torrent, C., Murru, A., Sanchez-Moreno, J., Patrizi, B., Girardi, P., Vieta, E., Colom, F., 2011. Mania and depression. Mixed, not stirred. J. Affect. Disord. 133, 105-113.

Pacchiarotti, I., Nivoli, A.M., Mazzarini, L., Kotzalidis, G.D., Sani, G., Koukopoulos, A., Scott, J., Strejilevich, S., Sanchez-Moreno, J., Murru, A., Valenti, M., Girardi, P., Vieta, E., Colom, F., 2013. The symptom structure of bipolar acute episodes: in search for the mixing link. J. Affect. Disord. $149,56-66$.

Pallaskorpi, S., Suominen, K., Ketokivi, M., Mantere, O., Arvilommi, P., Valtonen, H., Leppämäki, S., Isometsä, E., 2015. Five-year outcome of bipolar I and II disorders: findings of the Jorvi Bipolar Study. Bipolar Disord. 17, 363-374. 
Pallaskorpi, S., Suominen, K., Ketokivi, M., Valtonen, H., Arvilommi, P., Mantere, O., Leppamaki, S., Isometsa, E., 2017. Incidence and predictors of suicide attempts in bipolar I and II disorders: A 5-year follow-up study. Bipolar Disord. 19, 13-22.

Pavlova, B., Perlis, R.H., Alda, M., Uher, R., 2015. Lifetime prevalence of anxiety disorders in people with bipolar disorder: a systematic review and meta-analysis. Lancet Psychiatry. 2, 710717.

Popovic, D., Reinares, M., Goikolea, J.M., Bonnin, C.M., Gonzalez-Pinto, A., Vieta, E., 2012. Polarity index of pharmacological agents used for maintenance treatment of bipolar disorder. Eur. Neuropsychopharmacol. 22, 339-346.

Popovic, D., Reinares, M., Scott, J., Nivoli, A., Murru, A., Pacchiarotti, I., Vieta, E., Colom, F., 2013. Polarity index of psychological interventions in maintenance treatment of bipolar disorder. Psychother. Psychosom. 82, 292-298.

Popovic, D., Torrent, C., Goikolea, J.M., Cruz, N., Sanchez-Moreno, J., Gonzalez-Pinto, A., Vieta, E., 2014. Clinical implications of predominant polarity and the polarity index in bipolar disorder: $a$ naturalistic study. Acta Psychiatr. Scand. 129, 366-374.

Qiu, F., Akiskal, H.S., Kelsoe, J.R., Greenwood, T.A., 2017. Factor analysis of temperament and personality traits in bipolar patients: Correlates with comorbidity and disorder severity. J. Affect. Disord. 207, 282-290.

Rosa, A.R., Andreazza, A.C., Kunz, M., Gomes, F., Santin, A., Sanchez-Moreno, J., Reinares, M., Colom, F., Vieta, E., Kapczinski, F., 2008. Predominant polarity in bipolar disorder: diagnostic implications. J. Affect. Disord. 107, 45-51.

Vidal-Rubio, S.L., Balanza-Martinez, V., Cuenca, M., Vila-Frances, J., Vieta, E., Romeu, J.E., 2018. Duration of euthymia and predominant polarity in bipolar disorder. J. Affect. Disord. 241, 356-359.

Vieta, E., Berk, M., Wang, W., Colom, F., Tohen, M., Baldessarini, R.J., 2009. Predominant previous polarity as an outcome predictor in a controlled treatment trial for depression in bipolar I disorder patients. J. Affect. Disord. 119, 22-27.

Vieta, E., Berk, M., Schulze, T.G., Carvalho, A.F., Suppes, T., Calabrese, J.R., Gao, K., Miskowiak, K.W., Grande, I., 2018. Bipolar disorders. Nat. Rev. Dis. Primers. 4, 18008.

Yatham, L.N., Kennedy, S.H., Parikh, S.V, Schaffer, A., Bond, D.J., Frey, B.N., Sharma, V., Goldstein, B.I., Rej, S., Beaulieu, S., Alda, M., MacQueen, G., Milev, R.V., Ravindran, A., O'Donovan, C., McIntosh, D., Lam, R.W., Vazquez, G., Kapczinski, F., Mclntyre, R.S., Kozicky, J., Kanba, S., Lafer, B., Suppes, T., Calabrese, J.R., Vieta, E., Malhi, G., Post, R.M., Berk, M., 2018. Canadian Network for Mood and Anxiety Treatments (CANMAT) and International Society for Bipolar Disorders (ISBD) 2018 guidelines for the management of patients with bipolar disorder. Bipolar Disord. 20, 97-170.

Young, R.C., Biggs, J.T., Ziegler, V.E., Meyer, D.A., 1978. A rating scale for mania: reliability, validity and sensitivity. Br. J. Psychiatry. 133, 429-435. 
Table 1. Proportions of Predominant Polarity Depending on the Definition for the 188 Patients in the Jorvi Bipolar Study.

\begin{tabular}{|c|c|c|c|}
\hline & $\begin{array}{l}\text { ALL } \\
(\mathrm{N}=188) \\
\mathrm{N}(\%)\end{array}$ & $\begin{array}{l}\text { BD I } \\
(\mathrm{N}=88) \\
\mathrm{N}(\%)\end{array}$ & $\begin{array}{l}\text { BD II } \\
(\mathrm{N}=100) \\
N(\%)\end{array}$ \\
\hline \multicolumn{4}{|l|}{ Definition 1: } \\
\hline \multicolumn{4}{|c|}{ WITHOUT MIXED PHASES (mixed phases included in the total sum of phases) } \\
\hline Manic polarity & $21(11 \%)$ & $13(15 \%)$ & $8(8 \%)$ \\
\hline Depressive polarity & $44(23 \%)$ & $13(15 \%)$ & $31(31 \%)$ \\
\hline No polarity dominance & $123(65 \%)$ & $62(70 \%)$ & $61(61 \%)$ \\
\hline \multicolumn{4}{|c|}{ Definition 2: } \\
\hline \multicolumn{4}{|c|}{ MIXED PHASES (BD I) SUMMED WITH MANIC PHASES AND } \\
\hline \multicolumn{4}{|c|}{ DEPRESSIVE MIXED PHASES (BD II) SUMMED WITH DEPRESSIVE PHASES } \\
\hline Manic polarity & $30(16 \%)$ & $22(25 \%)$ & $8(8 \%)$ \\
\hline Depressive polarity & $68(36 \%)$ & $13(15 \%)$ & $55(55 \%)$ \\
\hline No polarity dominance & $90(48 \%)$ & $53(60 \%)$ & $37(37 \%)$ \\
\hline
\end{tabular}

${ }^{a}$ mixed and depressive mixed not specified for BD I patients 
Table 2. Baseline Sociodemographic and Clinical Characteristics of 188 BD Patients With Manic and Depressive Predominant Polarity and Without Polarity Dominance in the Jorvi Bipolar Study.

\begin{tabular}{|c|c|c|c|c|c|c|c|c|}
\hline \multirow[t]{2}{*}{ Variable } & \multicolumn{2}{|c|}{$\begin{array}{l}\text { Manic polarity } \\
\qquad N=30\end{array}$} & \multicolumn{2}{|c|}{$\begin{array}{l}\text { No polarity } \\
\text { dominance } \\
\qquad N=90\end{array}$} & \multicolumn{2}{|c|}{$\begin{array}{c}\text { Depressive } \\
\text { polarity } \\
N=68\end{array}$} & \multicolumn{2}{|c|}{ Sig. } \\
\hline & $\mathrm{N}$ & $\%$ & $\mathrm{~N}$ & $\%$ & $\mathrm{~N}$ & $\%$ & $\chi^{2}$ & $p$ \\
\hline Gender & & & & & & & 3.190 & 0.203 \\
\hline Male & 15 & 50.0 & 47 & 52.2 & 26 & 38.2 & & \\
\hline Female & 15 & 50.0 & 43 & 47.8 & 42 & 61.8 & & \\
\hline Marital status & & & & & & & 0.504 & 0.777 \\
\hline Not cohabiting & 17 & 56.7 & 54 & 60.0 & 37 & $54 \cdot 4$ & & \\
\hline $\begin{array}{l}\text { Married or } \\
\text { cohabiting }\end{array}$ & 13 & 43.3 & 36 & 40.0 & 31 & 45.6 & & \\
\hline Education & & & & & & & 3.360 & 0.186 \\
\hline $\begin{array}{l}\text { Professional } \\
\text { education }\end{array}$ & 20 & 66.7 & 58 & 64.4 & 35 & 51.5 & & \\
\hline $\begin{array}{l}\text { No professional } \\
\text { education }\end{array}$ & 10 & $33 \cdot 3$ & 32 & 35.6 & 33 & 48.5 & & \\
\hline Work Status & & & & & & & 3.818 & 0.148 \\
\hline Working & 9 & 30.0 & 24 & 26.7 & 28 & 41.2 & & \\
\hline Not working & 21 & 70.0 & 66 & 73.3 & 40 & 58.8 & & \\
\hline BD type & & & & & & & $\begin{array}{c}34.69 \\
4\end{array}$ & $\begin{array}{c}<0.00 \\
1\end{array}$ \\
\hline 1 & 22 & $73 \cdot 3$ & 53 & 58.9 & 13 & 19.1 & & \\
\hline II & 8 & 26.7 & 37 & 41.1 & 55 & 80.9 & & \\
\hline Depressive index phase & 9 & 30.0 & 54 & 60.0 & 42 & 61.8 & 9.723 & 0.008 \\
\hline First phase of illness & & & & & & & $\begin{array}{c}35 \cdot 45 \\
1\end{array}$ & $\begin{array}{c}<0.00 \\
1\end{array}$ \\
\hline $\begin{array}{l}\text { Mania or } \\
\text { hypomania }\end{array}$ & 17 & 56.7 & 15 & 16.9 & 9 & 13.4 & & \\
\hline MDE & 4 & 13.3 & 48 & 53.9 & 44 & 65.7 & & \\
\hline Mixed phase & 2 & 6.7 & 1 & 1.1 & 1 & 1.5 & & \\
\hline $\begin{array}{l}\text { Polyphasic } \\
\text { episode }\end{array}$ & 7 & 23.3 & 25 & 28.1 & 13 & 19.4 & & \\
\hline Rapid cycling & 6 & 20.0 & 32 & 35.6 & 22 & 32.4 & 2.515 & 0.284 \\
\hline Psychotic symptoms, lifetime & 21 & 70.0 & 48 & $53 \cdot 3$ & 27 & 39.7 & 8.001 & 0.018 \\
\hline Suicide attempts, lifetime & 13 & $43 \cdot 3$ & 50 & 55.6 & 34 & 50.0 & 1.454 & 0.483 \\
\hline Any anxiety disorder, lifetime & 10 & 33.3 & 45 & 50.0 & 44 & 64.7 & 8.708 & 0.013 \\
\hline Any substance abuse, lifetime & 12 & 40.0 & 55 & 61.1 & 29 & 42.6 & 7.033 & 0.030 \\
\hline Cluster A personality disorder & 5 & 16.7 & 10 & 11.1 & 4 & 5.9 & 2.857 & 0.240 \\
\hline Cluster B personality disorder & 7 & 23.3 & 30 & 33.3 & 16 & 23.5 & 2.255 & 0.324 \\
\hline Cluster C personality disorder & 5 & 16.7 & 22 & 24.4 & 16 & 23.5 & 0.798 & 0.671 \\
\hline
\end{tabular}




\begin{tabular}{|l|c|c|c|c|c|c|c|c|}
\hline Inpatient at intake & 9 & 30.0 & 40 & 44.4 & 14 & 20.6 & $\begin{array}{c}10.09 \\
1\end{array}$ & 0.006 \\
\hline & & & & & & & & \\
\hline & $\underline{\text { Mean }}$ & $\underline{\text { SD }}$ & $\underline{\text { Mean }}$ & $\underline{\text { SD }}$ & $\underline{\text { Mean }}$ & $\underline{\text { SD }}$ & & \\
\hline Age at entry, years $^{\mathrm{a}}$ & 39.3 & 12.8 & 38.2 & 11.0 & 36.1 & 13.2 & & 0.374 \\
\hline No. of phases, lifetime $^{\mathrm{a}}$ & 12.5 & 11.5 & 17.2 & 17.0 & 11.5 & 12.1 & & 0.776 \\
\hline
\end{tabular}

${ }^{a}$ Kruskall-Wallis test

$M D E=$ major depressive episode 
Table 3. Stability of the Polarity Types of ${ }_{145}$ Patients When Comparing the Time Up to Baseline and the 5-Year Follow-up Period in the Jorvi Bipolar Study.

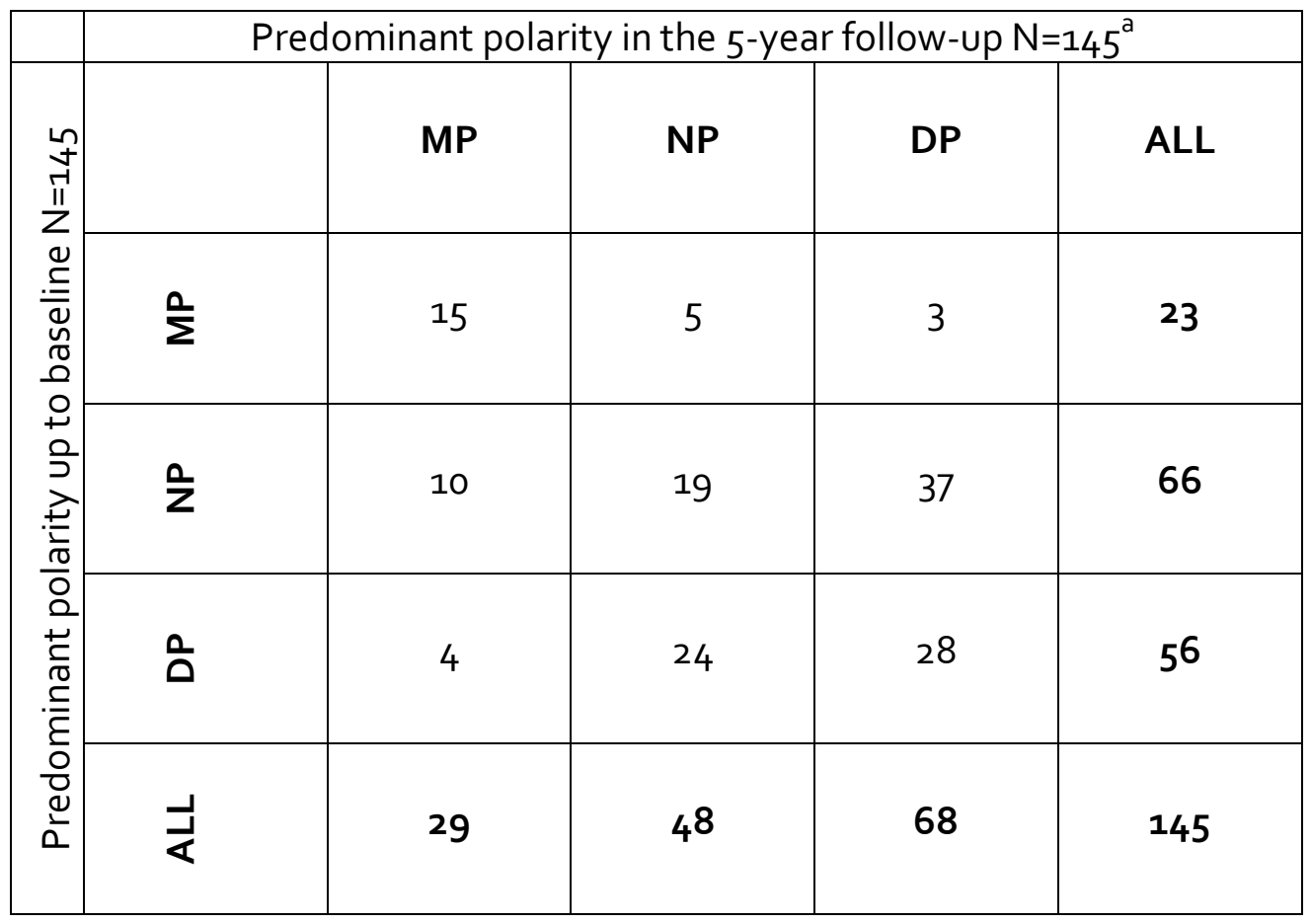

${ }^{a}$ Patients with no phases in follow-up excluded

$M P=$ manic predominant polarity

$D P=$ depressive predominant polarity

$N P=$ no predominant polarity 
Table 4. Multinomial Univariate Logistic Regression of Baseline Lifetime Comorbid Disorders and Clinical Variables for Polarity Groups in the Jorvi Bipolar Study. Depressive Polarity Group Is Set As the Reference Category.

\begin{tabular}{|c|c|c|c|c|c|c|c|c|c|c|c|c|}
\hline \multirow[b]{3}{*}{$\begin{array}{l}\text { Comorbid disorder/ } \\
\text { clinical variable }\end{array}$} & \multicolumn{6}{|c|}{ Non-adjusted model } & \multicolumn{6}{|c|}{ Adjusted model $^{*}$} \\
\hline & \multicolumn{3}{|c|}{ No polarity } & \multicolumn{3}{|c|}{ Manic polarity } & \multicolumn{3}{|c|}{ No polarity } & \multicolumn{3}{|c|}{ Manic polarity } \\
\hline & OR & $95 \% \mathrm{Cl}$ & $p$ & OR & $95 \% \mathrm{Cl}$ & $\mathrm{p}$ & OR & $95 \% \mathrm{Cl}$ & $\mathrm{p}$ & OR & $95 \% \mathrm{Cl}$ & $\mathrm{p}$ \\
\hline $\begin{array}{l}\text { Any anxiety disorder, } \\
\text { lifetime }\end{array}$ & 0.545 & $0.286-1.041$ & 0.066 & 0.273 & $0.110-0.676$ & 0.005 & 0.654 & $0.324^{-1.319}$ & 0.236 & 0.334 & $0.125-0.888$ & 0.028 \\
\hline $\begin{array}{l}\text { Any substance abuse, } \\
\text { lifetime }\end{array}$ & 2.113 & $1.113-4.011$ & 0.022 & 0.897 & $0.374-2.149$ & 0.807 & 1.585 & $0.776-3.234$ & 0.206 & 0.579 & $0.213-1.573$ & 0.284 \\
\hline $\begin{array}{l}\text { Cluster A personality } \\
\text { disorder }\end{array}$ & 2.000 & $0.599-6.675$ & 0.260 & 3.200 & $\begin{array}{l}0.794^{-} \\
12.895\end{array}$ & 0.102 & 1.937 & $0.534-7.031$ & 0.315 & $3 \cdot 314$ & $0.719-15.272$ & 0.124 \\
\hline $\begin{array}{l}\text { Cluster B personality } \\
\text { disorder }\end{array}$ & 1.625 & $0.798-3.310$ & 0.181 & 0.989 & $0.359-2.729$ & 0.983 & 1.679 & $0.766-3.681$ & 0.196 & 0.986 & $0.327-2.971$ & 0.980 \\
\hline $\begin{array}{l}\text { Cluster C personality } \\
\text { disorder }\end{array}$ & 1.051 & $0.503-2.200$ & 0.894 & 0.650 & $0.214-1.976$ & 0.448 & 1.213 & $0.541-2.723$ & 0.639 & 0.771 & $0.234-2.539$ & 0.668 \\
\hline $\begin{array}{l}\text { Psychotic symptoms, } \\
\text { lifetime }\end{array}$ & 1.317 & $0.957-1.813$ & 0.091 & 1.882 & $1.189-2.891$ & 0.007 & 1.045 & $0.727-1.502$ & 0.812 & 1.376 & $0.827-2.290$ & 0.220 \\
\hline First phase MDE & 0.612 & $0.318-1.177$ & 0.141 & 0.080 & $0.025-0.258$ & $<0.001$ & 0.589 & $0.280-1.240$ & 0.163 & 0.075 & $0.022-0.261$ & $<0.001$ \\
\hline First phase (hypo)manic & 1.306 & $0.534-3.197$ & $0.55^{8}$ & 8.427 & $\begin{array}{l}3.078- \\
23.074\end{array}$ & $<0.001$ & 1.232 & $0.469-3.235$ & 0.672 & 7.829 & $2.587-23.689$ & $<0.001$ \\
\hline Rapid cycling, baseline & 1.074 & $0.770-1.499$ & 0.674 & 0.723 & $0.432-1.209$ & 0.217 & 1.115 & $0.770-1.616$ & 0.563 & 0.738 & $0.421-1.296$ & 0.290 \\
\hline
\end{tabular}

*adjusted for age, gender, and BD type 


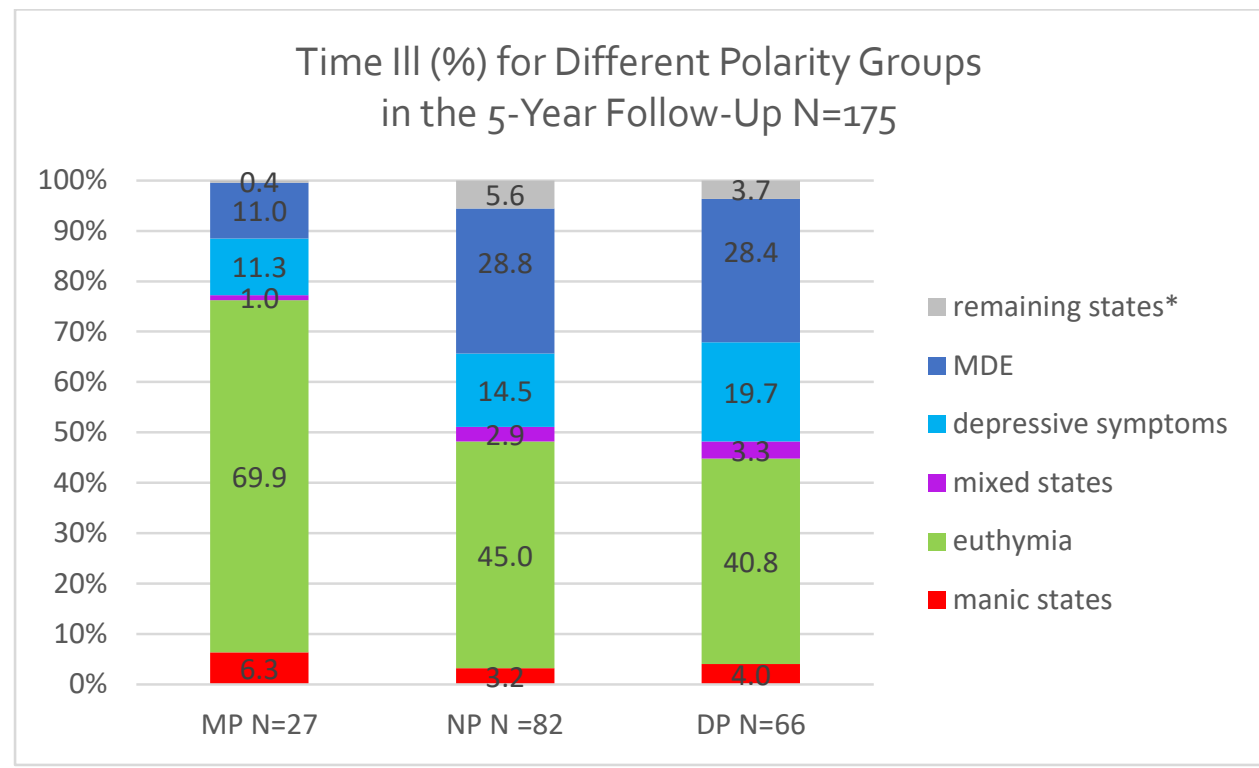

Time III (\%) For the Different Polarity Groups

Bipo $\mid \mathrm{N}=91$
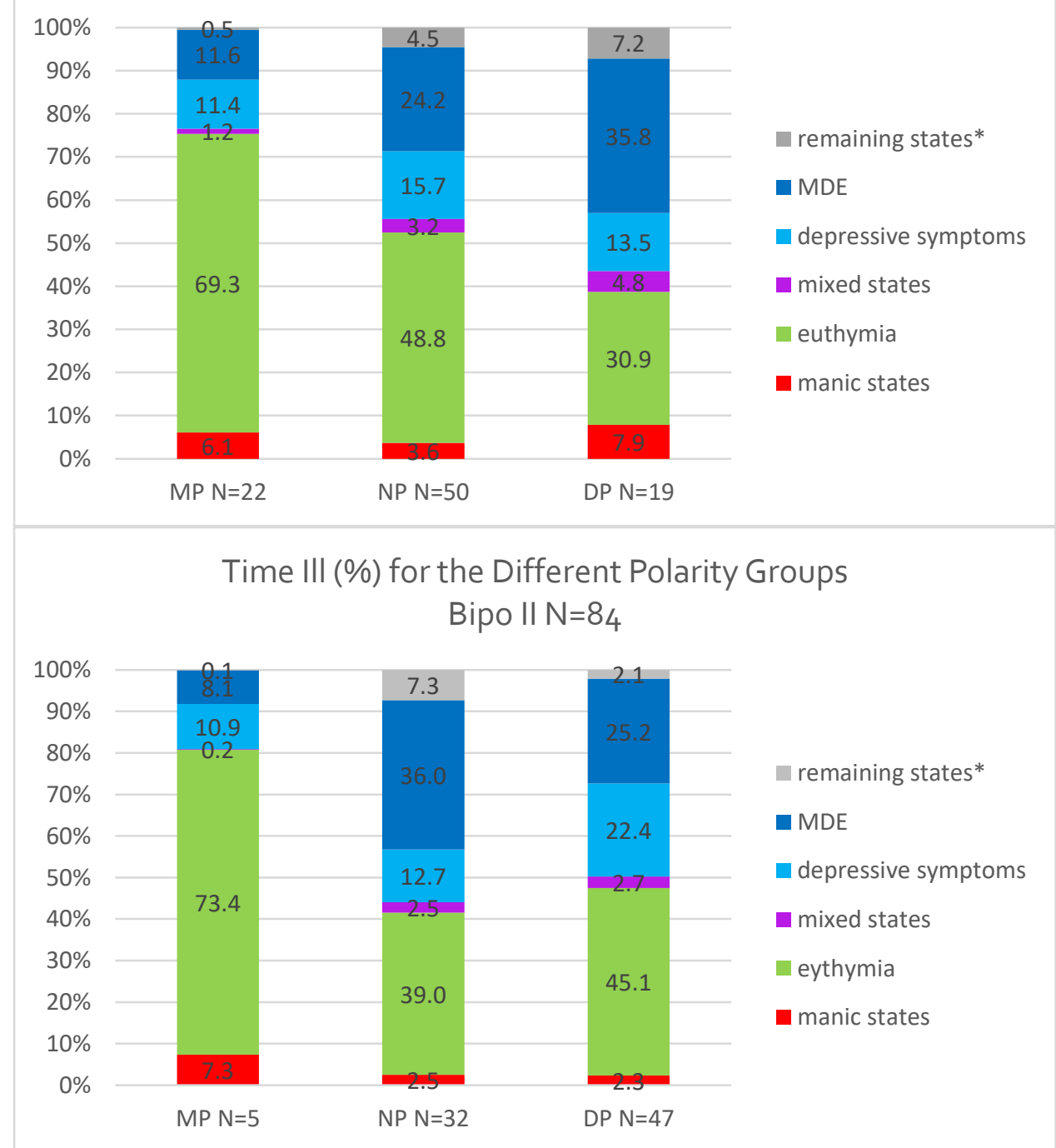

*Remaining states include hypomanic symptoms, cyclothymia, mood episodes caused by substance use, and not possible to classify. $M P=$ manic polarity, $N P=$ no polarity, $D P=$ depressive polarity

Figure 1. Time III for the Different Polarity Groups in the Jorvi Bipolar Study Five-Year Follow-up. 


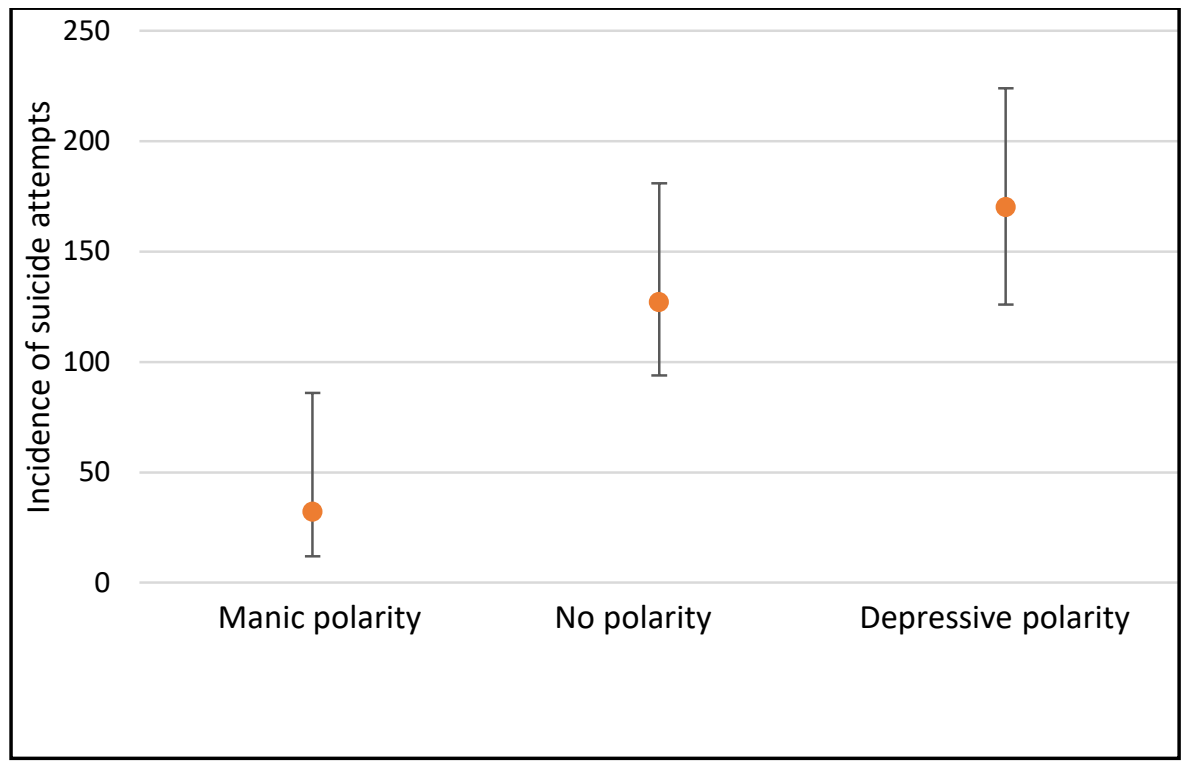

Figure 2. Incidence of Suicide Attempts in the Jorvi Bipolar Study 5-year Follow-up for Different Polarity Groups. 